\title{
Identification of BIRC6 as a novel intervention target for neuroblastoma therapy
}

Fieke Lamers ${ }^{1}$, Linda Schild ${ }^{1}$, Jan Koster ${ }^{1}$, Frank Speleman ${ }^{2}$, Ingrid $Ø r a^{3}$, Ellen M Westerhout ${ }^{1}$, Peter van Sluis ${ }^{1}$, Rogier Versteeg ${ }^{1}$, Huib N Caron ${ }^{4}$ and Jan J Molenaar ${ }^{1,5^{*}}$

\begin{abstract}
Background: Neuroblastoma are pediatric tumors of the sympathetic nervous system with a poor prognosis. Apoptosis is often deregulated in cancer cells, but only a few defects in apoptotic routes have been identified in neuroblastoma.

Methods: Here we investigated genomic aberrations affecting genes of the intrinsic apoptotic pathway in neuroblastoma. We analyzed DNA profiling data (CGH and SNP arrays) and mRNA expression data of 31 genes of the intrinsic apoptotic pathway in a dataset of 88 neuroblastoma tumors using the R2 bioinformatic platform (http://r2.amc.nl). BIRC6 was selected for further analysis as a tumor driving gene. Knockdown experiments were performed using BIRC6 lentiviral shRNA and phenotype responses were analyzed by Western blot and MTT-assays. In addition, DIABLO levels and interactions were investigated with immunofluorescence and co-immunoprecipitation.
\end{abstract}

Results: We observed frequent gain of the BIRC6 gene on chromosome 2, which resulted in increased mRNA expression. BIRC6 is an inhibitor of apoptosis protein (IAP), that can bind and degrade the cytoplasmic fraction of the pro-apoptotic protein DIABLO. DIABLO mRNA expression was exceptionally high in neuroblastoma but the protein was only detected in the mitochondria. Upon silencing of BIRC6 by shRNA, DIABLO protein levels increased and cells went into apoptosis. Co-immunoprecipitation confirmed direct interaction between DIABLO and BIRC6 in neuroblastoma cell lines.

Conclusion: Our findings indicate that BIRC6 may have a potential oncogenic role in neuroblastoma by inactivating cytoplasmic DIABLO. BIRC6 inhibition may therefore provide a means for therapeutic intervention in neuroblastoma.

Keywords: Neuroblastoma, BIRC6, DIABLO, Apoptosis, Cancer

\section{Background}

BIRC6 (also known as BRUCE or APOLLON) is a cytoplasmic protein with a dual role. Firstly, BIRC6 has an anti-apoptotic function in the intrinsic apoptotic pathway by antagonizing the pro-apoptotic DIABLO protein. BIRC6 can bind the cytoplasmic DIABLO fraction and induce ubiquitination and proteasomal degradation of this protein [1,2]. BIRC6 thereby protects against the

\footnotetext{
* Correspondence: j.j.molenaar@amc.uva.nl

'Department of Oncogenomics, Academic Medical Center, University of Amsterdam, Meibergdreef 15, PO box 22700, Amsterdam, AZ 1105, The Netherlands

${ }^{5}$ Department of Oncogenomics, M1-132, Academic Medical Center, University of Amsterdam, Meibergdreef 9, Amsterdam, AZ 1105, The Netherlands

Full list of author information is available at the end of the article
}

pro-apoptotic function of DIABLO. DIABLO is a mitochondrial protein which is released into the cytoplasm upon an apoptotic stimulus. This release is regulated by the levels of the BH3 family proteins, which induce pore formation in the mitochondrial membrane [3-5]. Cytoplasmic DIABLO can bind to the BIR domains of BIRC2 (cIAP1), BIRC3 (cIAP2) and BIRC4 (XIAP), thereby inhibiting the anti-apoptotic function of these proteins [6]. A second function of BIRC6 has been shown in recent studies where BIRC6 was required for abscission and membrane delivery during the midbody ring formation during cell division $[7,8]$.

BIRC6 is highly expressed in several types of cancer. BIRC6 over-expression in acute myeloid leukemia is correlated with a poor outcome [9]. A genome wide

\section{Biomed Central}


screening of chromosomal aberrations in Burkitt's lymphoma showed that a region of $2 p$ including the BIRC6 gene was gained in a few samples [10]. Additionally, high BIRC6 expression in colon cancer stem cells is associated with drug resistance [11].

Neuroblastoma are pediatric tumors that originate from the embryonal precursor cells of the sympathetic nervous system. High stage tumors have a poor prognosis with 20 to $40 \%$ overall survival [12-14]. BIRC6 is located on chromosome $2 \mathrm{p}$ in the region which shows frequent gain in neuroblastoma [12]. This region includes both $M Y C N$ and $A L K$, two well characterized oncogenes in neuroblastoma. Amplification of $M Y C N$ occurs in $20-30 \%$ of neuroblastoma and strongly correlates with a poor prognosis [12-15]. ALK was recently found to be mutated in $6-10 \%$ of primary neuroblastoma [16-20]. MYCN amplification and $A L K$ mutations seem independent of the gain of chromosome 2p [21] and therefore other additional tumor driving genes could be located on this frequently gained region.

The apoptotic pathway has been widely investigated in neuroblastoma and only a few tumor driving events have been described. TP53 is mostly intact in primary neuroblastoma although functional defects in the p53 pathway have been described [22]. Caspase 8 (CASP8) is hypermethylated and thereby inactivated in some neuroblastoma resulting in an inactive extrinsic apoptotic pathway [23]. The IAP BIRC5 (Survivin) is located on the chromosome $17 \mathrm{q}$ region which is frequently gained in neuroblastoma and high BIRC5 expression correlates with a poor prognosis [24-26]. Also, the anti-apoptotic mitochondrial $B C L 2$ protein is highly expressed in neuroblastoma. Targeted inhibitors against BIRC5 [27-32] and BCL2 [33] are currently being tested for clinical implementation, however, the poor prognosis of high grade neuroblastoma makes the identification of additional targets for therapeutic intervention desirable.

To identify patterns in aberrations of genes involved in intrinsic apoptotic signaling we combined high throughput analysis of DNA copy number and mRNA expression of these genes in a dataset of 88 neuroblastoma tumors. We found BIRC5 and BIRC6 to be frequently gained and CASP9 often lost. Since BIRC6 was not previously evaluated in a neuroblastoma model, we studied the potency of BIRC6 as a potential new target for neuroblastoma therapy. Silencing of BIRC6 induced apoptosis and up-regulation of DIABLO. We established BIRC6 to physically interact with DIABLO, indicating that BIRC6 can degrade DIABLO very effectively.

\section{Methods}

\section{Patient samples}

We used a neuroblastoma tumor panel for Affymetrix Microarray analysis containing 88 primary neuroblastoma tumor samples of untreated patients of which 87 neuroblastoma tumor samples were also used for CGH analysis and SNP array [34]. All neuroblastoma samples were residual material obtained during surgery for diagnostic purposes and immediately frozen in liquid nitrogen. Ethical approval of the Dutch Medical Ethical Committee was not needed for the use of surplus materials. However, informed consent was taken from the parents of the patients for use of this material which is archived at the Academic Medical Center from the University of Amsterdam. The data were deposited in the NCBI Gene Expression Omnibus (http://www.ncbi. nlm.nih.gov/geo/) under accession number GSE16476 [35]. Public available neuroblastoma datasets we used were of Delattre [36] and Lastowska (geo ID: gse13136). Public available datasets were used for comparing neuroblastoma with normal tissues (Roth dataset, geo ID: gse3526) and adult tumors (EXPO dataset, geo ID: gse2109).

\section{Affymetrix mRNA expression analysis}

Total RNA of neuroblastoma tumors was extracted using Trizol reagent (Invitrogen, Carlsbad, CA) according to the manufacturer's protocol. RNA concentration and quality were determined using the RNA 6000 nano assay on the Agilent 2100 Bioanalyzer (Agilent Technologies). Fragmentation of cRNA, hybridization to hg-u133 plus 2.0 microarrays and scanning were performed according to the manufacturer's protocol (Affymetrix inc).

\section{Array $\mathrm{CGH}$ analysis}

High-molecular-weight DNA was isolated from tumor tissue by a standard salt-chloroform extraction method [37]. For reference DNA we obtained healthy tissue. We used a custom $44 \mathrm{~K}$ Agilent aCGH chip, enriched for critical regions of loss/gain for neuroblastoma (10 kb resolution), miRNAs/T-UCRs (5 oligos/gene) and cancer gene census genes (5 oligos/gene) (Agilent Technologies). A total of $150 \mathrm{ng}$ of tumor and reference DNA was labeled with $\mathrm{Cy} 3$ and $\mathrm{Cy} 5$, respectively (BioPrime ArrayCGH Genomic Labeling System, Invitrogen). Further processing was done according to the manufacturer's guidelines. Features were extracted using the feature extraction v10.1.0.0.0 software program. Data were further analyzed using the R2 web application (see below). Circular binary segmentation was used for scoring the regions of gain, amplification and deletion.

\section{Whole-genome genotyping}

Tumor DNA was extracted as previously described, quantified with NanoDrop and the quality was determined by the Abs $260 / 280$ and $230 / 260$ ratio. SNP arrays were processed for analysis of copy number 
variations with the Infinium II assay on Human370/660quad arrays containing $>370000 />660000$ markers and run on the Illumina Beadstation (Swegene Centre for Integrative Biology, Lund University - SCIBLU, Sweden) according to the manufacturer's recommendations. Raw data were processed using Illumina's BeadStudio software suite (Genotyping module 3.0 ), producing report files containing normalized intensity data and SNP genotypes. Subsequently, $\log 2$ Ratio and B-allele frequency data were imported into the R2 web application for detailed analysis and comparison with the CGH and expression data.

\section{Bioinformatics}

All data were analyzed using the R2 web application, which is publicly available at http://r2.amc.nl. The expression data were normalized with the MAS5.0 algorithm within the GCOS program of Affymetrix Inc. Target intensity was set to 100 . For scoring genomic aberrations of the 31 included genes (see below and Table 1), we considered CGH aberrant if the logfold value was more than 0.45 for gain or less than -0.45 for loss and if a breaking point was clearly visible. We excluded whole chromosome gains or losses. Also, the detected gains or losses had to be confirmed by SNP array.

\section{Cell lines}

All cell lines were grown in Dulbecco Modified Eagle Medium (DMEM), supplemented with 10\% fetal calf serum, $10 \mathrm{mM} \mathrm{L}$-glutamine, $10 \mathrm{U} / \mathrm{ml}$ penicillin/streptomycin, Non Essential Amino Acids (1x) and $10 \mu \mathrm{g} / \mathrm{ml}$ streptomycin. Cells were maintained at $37^{\circ} \mathrm{C}$ under $5 \%$ $\mathrm{CO}_{2}$. For primary references of these cell lines, see Molenaar et al. [35].

\section{Lentiviral shRNA production and transduction}

Lentiviral particles were produced in HEK293T cells by co-transfection of lentiviral vector containing the short hairpin RNA (shRNA) with lentiviral packaging plasmids pMD2G, pRRE and pRSV/REV using FuGene HD. Supernatant of the HEK293T cells was harvested at 48 and $72 \mathrm{~h}$ after transfection, which was purified by filtration and ultracentrifugation. The concentration was determined by a p24 ELISA. Cells were plated at a $10 \%$ confluence. After $24 \mathrm{~h}$ cells were transduced with lentiviral DIABLO shRNA (Sigma, 'E8': TRCN0000004511 and 'E9': TRCN0000004512) or BIRC6 shRNA (Sigma, 'C7': TRCN0000004157 and 'C11': TRCN0000004161) in various concentrations (Multiplicity of infection (MOI): 1-3). SHC-002 shRNA (non-targeting shRNA: CAACAAGATGAAGAGCACCAA) was used as a negative control. Medium was refreshed $24 \mathrm{~h}$ after transduction and puromycin was added to select for transduced cells. Protein was
Table 1 Selected genes in the intrinsic apoptotic pathway

\begin{tabular}{|c|c|}
\hline Gene family or category & Gene (alias) \\
\hline \multirow[t]{6}{*}{ Anti-apoptotic members of BCL2 family } & $\mathrm{BCL} 2$ \\
\hline & MCL1 \\
\hline & BCL2L1 (BCLXL) \\
\hline & $\mathrm{BCL} 2 \mathrm{~L} 2(\mathrm{BCLW})$ \\
\hline & $\mathrm{BCL} 2 \mathrm{~A} 1$ \\
\hline & BCL2L10 \\
\hline \multirow[t]{9}{*}{ Pro-apoptotic members of BCL2 family } & BBC3 (PUMA) \\
\hline & BCL2L11 (BIM) \\
\hline & $\mathrm{BID}$ \\
\hline & PMAIP1 (NOXA) \\
\hline & $\mathrm{BAD}$ \\
\hline & BIK \\
\hline & HRK \\
\hline & BCL2L14 \\
\hline & BMF \\
\hline \multirow[t]{2}{*}{ Mitochondrial permeabilization } & BAX \\
\hline & BAK1 \\
\hline \multirow[t]{3}{*}{ Cytoplasmic pro-apoptotic genes } & DIABLO \\
\hline & CYCS \\
\hline & APAF1 \\
\hline \multirow{4}{*}{$\begin{array}{l}\text { Caspases, activated by mitochondrial } \\
\text { apoptotic pathway }\end{array}$} & CASP3 \\
\hline & CASP6 \\
\hline & CASP7 \\
\hline & CASP9 \\
\hline \multirow[t]{5}{*}{ IAPs } & NAIP \\
\hline & XIAP \\
\hline & BIRC5 \\
\hline & BIRC6 \\
\hline & BIRC7 \\
\hline \multirow[t]{2}{*}{ Activation of mitochondrial apoptotic pathway } & TP53 \\
\hline & CASP2 \\
\hline
\end{tabular}

harvested $72 \mathrm{~h}$ after transduction and analyzed by Western blot.

\section{Compounds}

ABT263, a small molecule BCL2 inhibitor, was dissolved in DMSO to a concentration of $20 \mathrm{mM}$ as stock solution. A final concentration of $200 \mathrm{nM} \mathrm{ABT263}$ was used. For the experiment using this compound we chose SJNB12 instead of IMR32 or SKNSH for its high expression of BCL2 and its subsequent high sensitivity to this compound [33].

Z-Val-Asp(OMe)-Val-Ala-Asp(OMe)-FMK (ZVDVADFMK, a widely used CASP2 inhibitor; R\&D systems) was 
added to the cells following manufacturer's protocol in a concentration of $20 \mu \mathrm{M}$.

\section{Western blotting}

Attached and floating cells were harvested on ice $72 \mathrm{~h}$ after transduction with shRNA. Cells were lyzed with Laemmlibuffer (20\% glycerol, 4\% SDS, $100 \mathrm{mM}$ Tris $\mathrm{HCl} \mathrm{pH} 6.8$ in $\mathrm{mQ}$ ). Protein concentrations were quantified with RC-DC protein assay (Bio-Rad, Hercules, USA). Lysates were separated on a 10\% SDS-Page gel and transferred onto a blotting membrane (Millipore, IPFL00010). Blocking and incubation were performed in OBB according to manufacturer's protocol (LI-COR). Primary antibodies used were anti-BIRC6 (Abcam, ab19609), anti-DIABLO (Abcam, ab32023), anti-PARP (Cell Signaling: 9542) and anti-BCL2 (Cell Signalling; 2872). Protein loading was checked by anti- $\beta$-actin (Abcam, ab6276) or anti- $\alpha$-tubulin (Sigma, T5168). The secondary antibodies used were provided by LI-COR. Proteins were visualized with the Odyssey bioanalyzer (LI-COR).

\section{In cell western}

Cells were fixed with $4 \%$ paraformaldehyde for $20 \mathrm{~min}$ $48 \mathrm{~h}$ after transduction with BIRC6 shRNA. Blocking and incubation were performed in $\mathrm{OBB}$ according to manufacturer's protocol (LI-COR). Primary antibodies used were anti-BIRC6 (BD Biosciences, 611193) and anti- $\beta$-actin mouse monoclonal (Abcam, ab6276). Proteins were visualized with the Odyssey bioanalyzer (LICOR) and quantified and corrected for $\beta$-actin using the Odyssey software.

\section{Immunofluorescence}

Cells were grown on glass slides in 6-well plates and were fixed with $4 \%$ paraformaldehyde in PBS $48 \mathrm{~h}$ after transduction. We used anti-DIABLO (Abcam, ab32023) as a primary antibody, and anti-rabbit (Alexa, 11012) as a secondary antibody. Mitochondria were stained using Mitotracker (Invitrogen, M22426). Antibodies were dissolved in 5\% ELK in PBS/0.2\% tween-20. Slides were stained with DAPI (1:1000) in vectashield (Vector Laboratories).

\section{Cell fractionation}

Protein was harvested and fractionated using the Subcellular Proteome Extraction Kit according to manufacturer's protocol (Novagen, 539790). Fraction I (cytosol) and II (membrane/organelle) were used for Western blot.

\section{Co-immunoprecipitation}

Cells were lyzed in a buffer containing $150 \mathrm{mM} \mathrm{NaCl}$, $50 \mathrm{mM}$ Hepes, $5 \mathrm{mM}$ EDTA, 0.3\% NP-40, $10 \mathrm{mM}$ $\beta$-glycerophosphate, $6 \%$ glycerol, protease inhibitors (Complete mini, Roche) and Phosphatase inhibitors
(5 mM NaF, $1 \mathrm{mM} \mathrm{Na2VO3).} \mathrm{The} \mathrm{antibody} \mathrm{used} \mathrm{for}$ IP was anti-BIRC6 (Abcam, ab19609); negative controls were anti-flag (Cell Signaling, 2368) and protein without antibody. Protein-G agarose beads (Roche) and antibody were incubated for pre-coupling overnight after which lysates were added and incubated overnight. Immunocomplexes were washed, heated at $95^{\circ} \mathrm{C}$ for $10 \mathrm{~min}$ and loaded on a gel for Western blot. Primary antibodies used were anti-BIRC6 and antiDIABLO (Abcam; ab32023). Blots were incubated overnight with primary antibodies, after which a one hour incubation step with anti-rabbit IgG (Cell Signaling; 3678) was performed followed by incubation with the secondary antibody provided by LI-COR.

\section{MTT-assay}

Cells were seeded at $30 \%$ confluence in a 48 -well plate, transduced with BIRC6 shRNA and after $24 \mathrm{~h}$ treated with ZVDVAD. Seventy-two hours after treatment, $25 \mu \mathrm{l}$ of Thiazolyl blue tetrazolium bromide (MTT, Sigma M2128) was added. After 4-6 h of incubation, $250 \mu \mathrm{l}$ of $10 \%$ SDS, $0.01 \mathrm{M} \mathrm{HCl}$ was added to stop the reaction. The absorbance was measured at $570 \mathrm{~nm}$ and $720 \mathrm{~nm}$ using a plate-reader (Biotek).

\section{Results}

Gain of BIRC5 and BIRC6 and loss of CASP9 in neuroblastoma tumors

To identify patterns in the aberrations of genes involved in intrinsic apoptotic signaling, we combined high throughput analysis of DNA copy number and mRNA expression of these genes. We included all 31 genes that are directly involved in the mitochondrial apoptotic pathway and their downstream target genes (Table 1). Array CGH data of 87 primary neuroblastoma tumor samples were analyzed for copy number variations of the 31 genes included in our intrinsic apoptotic gene panel. Binary segmentation data was used to score the DNA copy number variations and they were subsequently confirmed using log fold data from SNP array analyses of the same tumors. Only three genes show DNA copy number aberrations at a frequency above 10\% (Figure 1a). The BIRC5 gene, which is located in the smallest region of overlap (SRO) of gain of chromosomal band 17q25 [12], is gained in $49 \%$ of the tumors. CASP9 is located at the SRO of deletions of $1 \mathrm{p} 36$ [12] and it is lost in $30 \%$ of the tumors. BIRC6, which is located on 2p22, is gained in $24 \%$ of the neuroblastoma tumors. Distal chromosome $2 \mathrm{p}$ is a known region of gain in neuroblastoma. BIRC6 is not located in the SRO of this gained region, but is gained in $84 \%$ of the tumors with $2 \mathrm{p}$ gain (Figure $1 \mathrm{~b}$ ). Of these three genes, BIRC6 was not studied before in neuroblastoma. We therefore investigated whether the gain of BIRC6 resulted in aberrant expression. We compared 


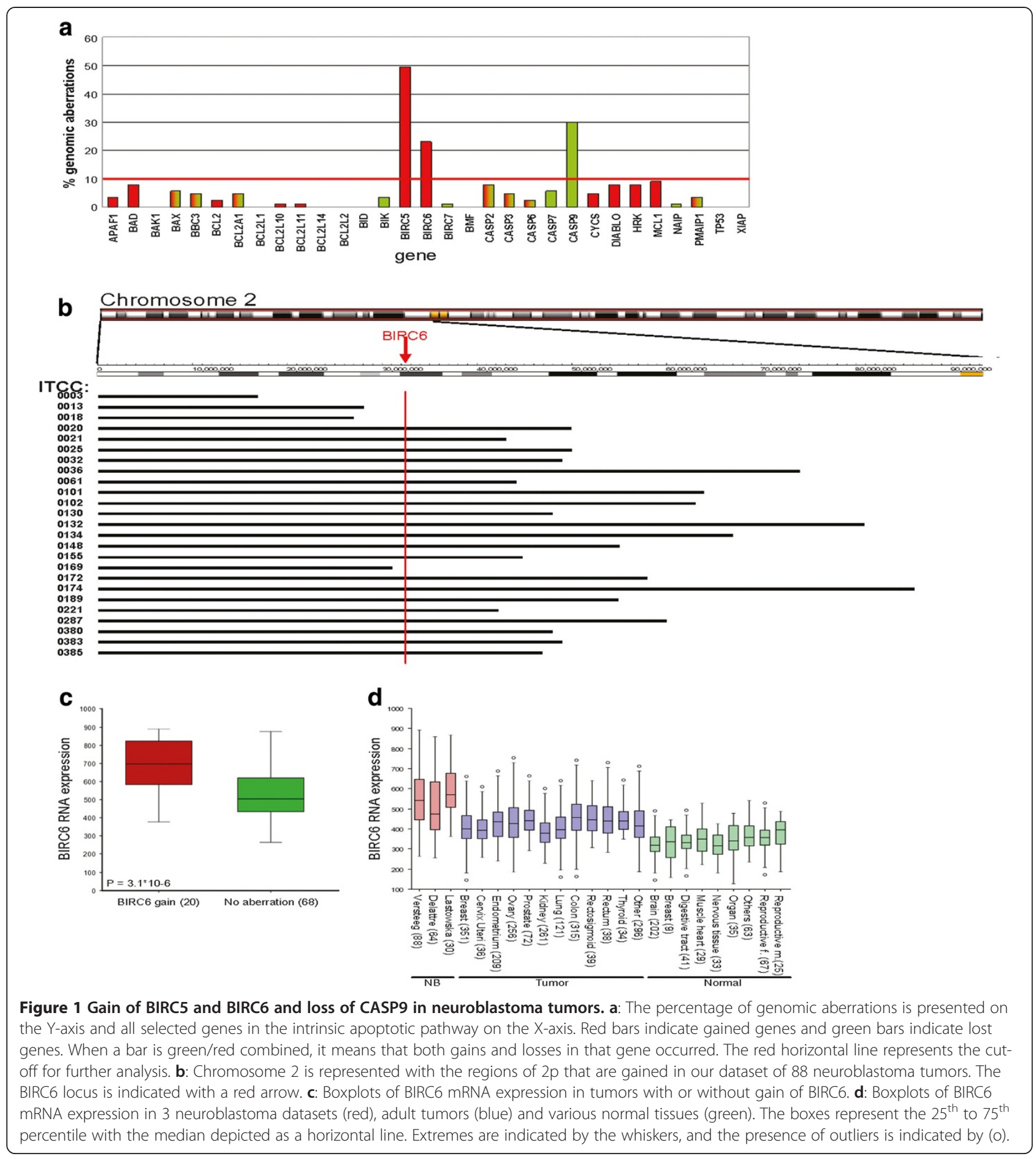

BIRC6 expression in tumors with and without BIRC6 gain, which shows that tumors with BIRC6 gain have significantly higher BIRC6 RNA levels (Student T-test: $\mathrm{P}=3.1^{*} 10^{-6}$ ) (Figure 1c). Moreover, BIRC6 is also highly expressed compared to several adult tumors and various normal tissues (Figure 1d). These findings suggest that the aberrant expression of BIRC6 is at least partially caused by genomic aberrations often occurring in neuroblastoma tumors.

\section{BIRC6 knockdown induces apoptosis in neuroblastoma cells}

We investigated whether the high BIRC6 levels indeed counteract apoptosis in neuroblastoma. We used 2 
lentiviral shRNAs targeting different parts of the coding sequence of BIRC6. SKNSH, one of the neuroblastoma cell lines with the highest BIRC6 expression, was transduced with these vectors (Figure 2a). BIRC6 is a $528 \mathrm{kD}$ protein and difficult to assess with Western blot. Therefore we first analyzed BIRC6 protein levels by in cell
Western. For this method cells are fixed directly in the culture well and stained with a BIRC6 antibody. Analysis shows concentration dependent down-regulation of BIRC6 protein with both BIRC6 shRNAs at $48 \mathrm{~h}$ after transduction (Figure 2b). Although less optimal, we can confirm BIRC6 down-regulation using Western blot

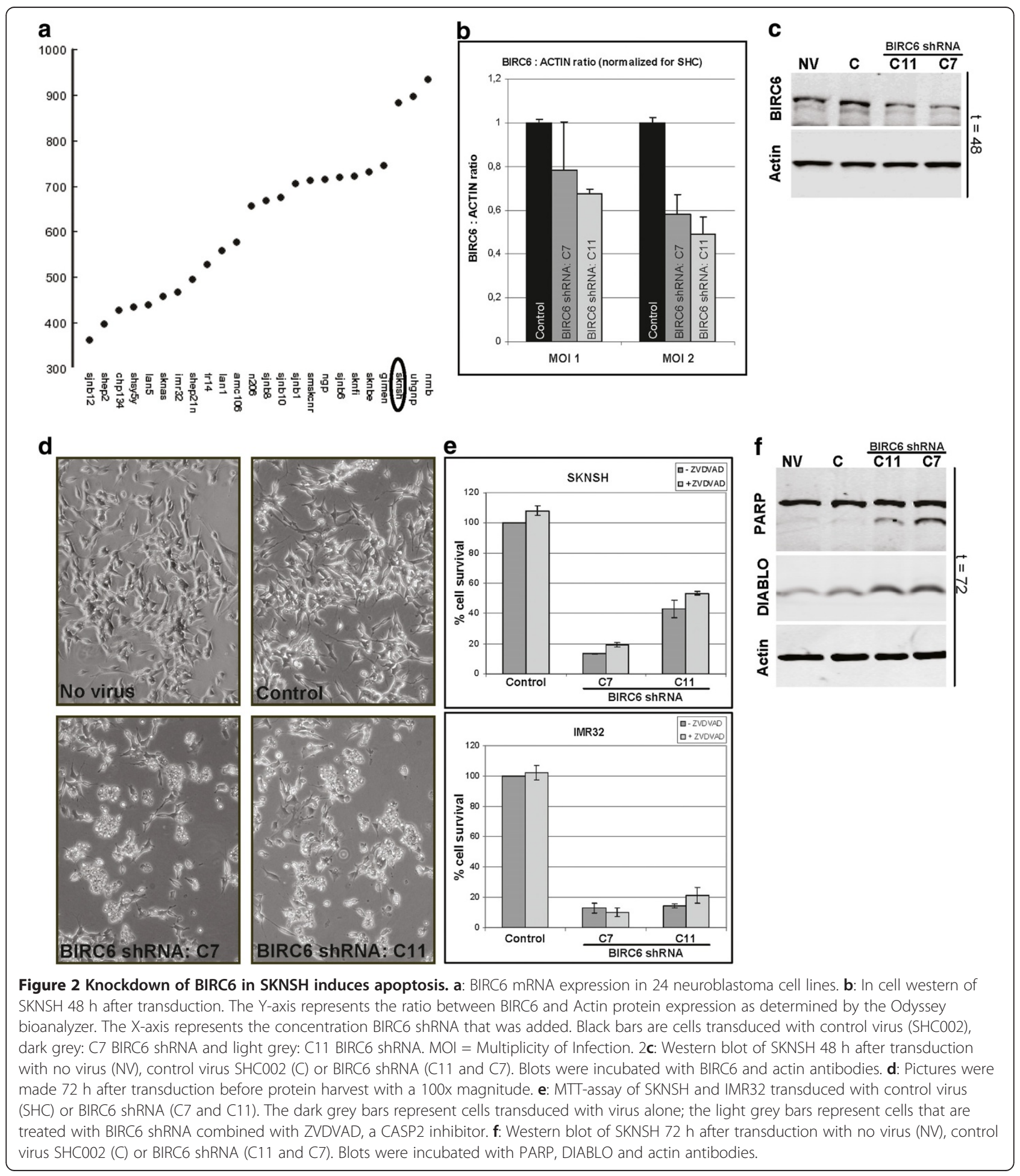




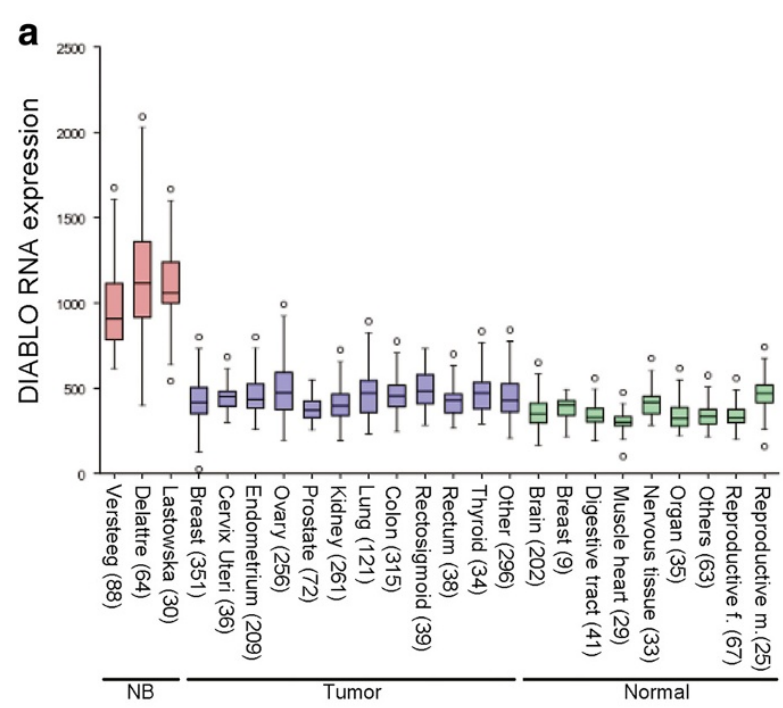

C
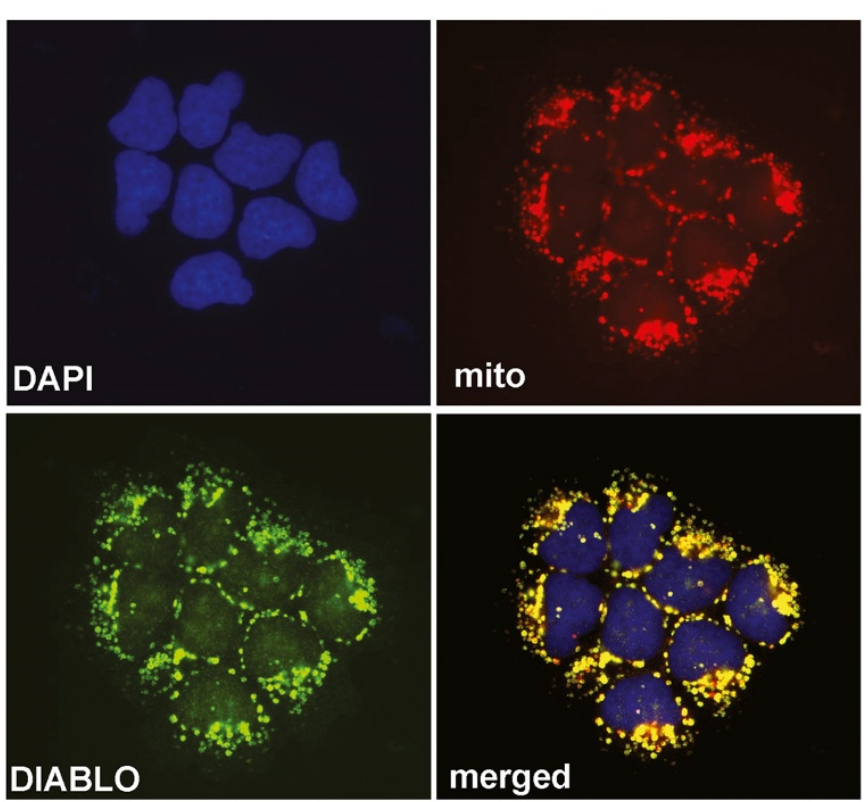

- protein b

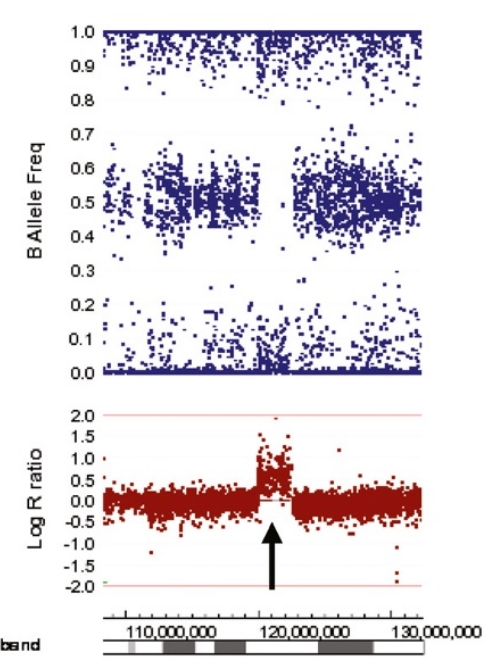

d

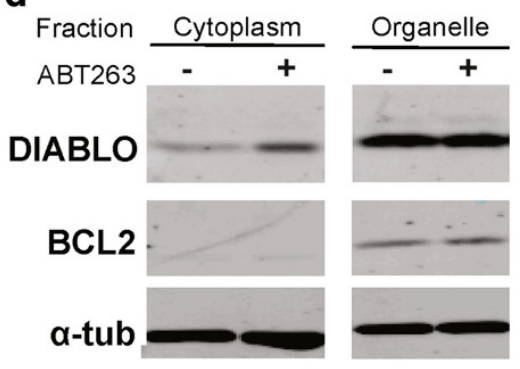

e

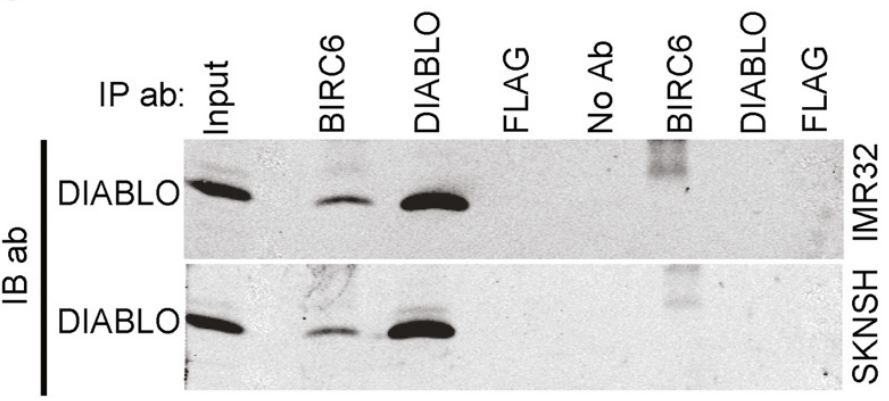

Figure 3 (See legend on next page.) 
(See figure on previous page.)

Figure 3 DIABLO mRNA and protein expression. 3a: Boxplots of DIABLO mRNA expression in 3 neuroblastoma datasets (red), adult tumors (blue) and various normal tissues (green). The boxes represent the $25^{\text {th }}$ to $75^{\text {th }}$ percentile with the median depicted as a horizontal line. Extremes are indicated by the whiskers, and the presence of outliers is indicated by (o). $3 \mathbf{b}$ : Array CGH of NGP of the region of chromosome 12 224.31 in which DIABLO is located (arrow). Both the B allele frequency (top) and the Log R ratio (bottom) are shown. The chromosome region is shown underneath the picture. 3c: Immunofluorescence of untreated IMR32 cells. Blue is DAPI, red is mitotracker, green is DIABLO antibody. In the right lower corner the merged pictures are shown. 3d: Cell fractionation of SJNB12 cells $24 \mathrm{~h}$ after addition of ABT263. The cytoplasmic fraction (cyto) and organelle fraction (organelle) are shown. Blots were incubated with DIABLO, BCL2 and a-tubulin antibodies. 3e: Co-immunoprecipitation of IMR32 (top) and SKNSH (bottom) with BIRC6 and DIABLO antibodies. Negative control was the immunoprecipitation antibody Flag. Also a protein sample without antibody and for every antibody a sample without protein was used as negative control. Both blots were incubated with DIABLO antibody. IP antibodies are indicated above the blots.

(Figure 2c). We then investigated whether BIRC6 silencing induced apoptosis. Light microscopy shows a decreased cell number and cell death at $72 \mathrm{~h}$ after BIRC6 silencing (Figure 2d). This is confirmed by MTT assays, which shows strongly reduced cell viability after transduction with both BIRC6 shRNAs (Figure 2e, dark grey bars). This phenotype is caused by an apoptotic response demonstrated by PARP cleavage at $72 \mathrm{~h}$ after transduction with both BIRC6 shRNAs on western blot (Figure 2f). These findings confirm an anti-apoptotic role for BIRC6 in neuroblastoma cells.

\section{High BIRC6 levels keep cytoplasmic DIABLO levels low}

The BIRC6 protein functions both by silencing of DIA$\mathrm{BLO}$ and in the formation of the midbody ring during cell division. Inhibition of each of these functions can result in cell death. We therefore investigated which process causes apoptosis after BIRC6 silencing in neuroblastoma. Apoptosis induced after inhibiting the midbody-related function of BIRC6 has been found to be mediated by CASP2 $[7,8,38]$. We inhibited CASP2 by ZVDVAD, a widely used CASP2 inhibitor [39-41] that we have previously used to show that apoptosis induced by silencing of BIRC5 is mediated by CASP2 [26]. ZVDVAD however does not inhibit apoptosis induced by BIRC6 knockdown in SKNSH and IMR32 cells (Figure 2e). This indicates that this process is not CASP2-mediated, implying that the role of BIRC6 in neuroblastoma is not essential for completion of cell division during midbody ring formation.

Alternatively, BIRC6 functions as an IAP that binds DIABLO in the cytoplasm thereby inducing ubiquitination and degradation of DIABLO [1,2]. DIABLO mRNA expression levels in neuroblastoma tumors are surprisingly high compared to other types of tumors and compared to normal tissue (Figure 3a). Moreover, we confirm an amplification of a region on the chromosome $12 \mathrm{q}$ arm in the neuroblastoma cell line NGP, which includes the DIABLO locus (Figure 3b) [42]. We therefore investigated whether the high BIRC6 expression allows neuroblastoma cells to survive the high levels of the pro-apoptotic protein DIABLO. DIABLO is a mitochondrial protein, which translocates to the cytoplasm after apoptotic stimuli where it can be degraded by
BIRC6. We investigated the cellular localization of DIABLO and immunofluorescence indeed shows a clear localization of DIABLO within the mitochondria (Figure 3c), which is confirmed by cell fractionation showing that the majority of DIABLO is localized in the cell organelle fraction (Figure 3d). To test whether DIABLO can be functionally activated upon an apoptotic stimulus, we treated neuroblastoma cells with the BCL2 inhibitor ABT263, which results in stimulation of pore formation in the mitochondria [43]. Cell fractionation indicates that the cytosolic DIABLO levels increases 24 $\mathrm{h}$ after ABT263 treatment (Figure 3d), demonstrating that DIABLO can be released from the mitochondria and stimulate apoptosis.

Untreated cells have low cytoplasmic DIABLO levels (Figure 3d). These levels are probably restricted by BIRC6 activity. To test this hypothesis, we first investigated by a co-immunoprecipitation analysis whether BIRC6 and DIABLO physically interact in neuroblastoma cells. Cell lysates of SKNSH and IMR32 cells were immunoprecipitated with a BIRC6 antibody. Western blot analysis of these precipitates with a DIABLO antibody shows a strong signal at the correct position for DIABLO. This confirms a physical interaction between both proteins (Figure 3e). Finally, we investigated whether silencing of BIRC6 results in increased DIABLO protein levels. Western blot analysis of SKNSH cells treated with two different shRNAs for BIRC6 shows that the silencing of BIRC6 induced by both hairpins results in a clear increase of DIABLO protein levels (Figure 2f).

These experiments suggest that BIRC6 may effectively inactivate cytoplasmic DIABLO in neuroblastoma cells and can thereby prevent an apoptotic response.

\section{Discussion and conclusions}

In this paper we analyzed aberrations in gene copy number and mRNA expression of genes directly involved in the intrinsic apoptotic pathway in neuroblastoma. BIRC6, known as an inhibitor of the pro-apoptotic protein DIABLO, showed gene copy number gains and increased expression. Silencing of BIRC6 with two shRNAs targeting different parts of the coding sequence resulted in increased cytoplasmic DIABLO levels and 
triggered apoptosis. As expected, BIRC6 directly interacted with DIABLO proteins.

The apoptotic response in neuroblastoma cells upon BIRC6 silencing occurs in a background of surprisingly high DIABLO expression levels. High cytoplasmic levels of DIABLO can be tumor inhibitory through binding of IAPs in the cytoplasm. We suggest two mechanisms why high DIABLO expression does not induce apoptosis in neuroblastoma. Firstly, we show that the major fraction of DIABLO protein has a mitochondrial localization. This mitochondrial sequestration is probably mediated by the exceptionally high levels of BCL2, which occurs in most neuroblastoma tumors [33]. Targeted inhibition of BCL2 caused an increase in cytoplasmic DIABLO levels, suggesting that sequestration of DIABLO in the mitochondria occurs by inhibition of pore formation through BCL2. Secondly, we showed that DIABLO is effectively bound by BIRC6 in neuroblastoma and that DIABLO levels increase upon silencing of BIRC6. This suggests an effective degradation of cytoplasmic DIABLO by BIRC6. We did not find a correlation between BIRC6 expression and prognosis or prognostic markers. We also did not find a correlation between BIRC6 and BCL2 or DIABLO mRNA expression (data not shown). This can be explained by the observation that the expression of both BCL2 and DIABLO is generally high in all neuroblastoma tumor samples and not in just a subset [33]. The function of high mitochondrial DIABLO levels in neuroblastoma remains elusive. Other proapoptotic proteins in the mitochondria, like cytochrome C, have shown to be involved in energy metabolism [44] but no such mechanism has been found for DIABLO yet.

The interaction of BIRC6 with CASP9, which has been reported previously $[1,2,45]$, has not been validated in this paper. Since CASP9 has been shown to be functionally active in neuroblastoma despite its location on a frequently lost region [46], it would be interesting to investigate whether there is an additional inhibition of this protein by BIRC6 in neuroblastoma cells.

Release of the strongly increased mitochondrial DIABLO levels would offer a therapeutic potential in neuroblastoma. This suggests that the proteins that impair the pro-apoptotic function of DIABLO could be effective drug targets. The previously shown efficacy of targeted BCL2 inhibition could relate to high DIABLO levels [33]. Moreover, direct BIRC6 inhibition would also increase the cytoplasmic pro-apototic function of DIABLO. BIRC6 inhibitors are not available at this moment, but targeted drug development might be worth considering. BIRC6 is not located on the SRO of $2 \mathrm{p}$, but it is frequently gained and functionally active and we therefore consider BIRC6 as a potentially important player in the dysfunction of apoptosis in neuroblastoma. The BIRC6 gene is validated as a novel therapeutic target. If BIRC6 inhibitors are developed, a combined inhibition of BIRC6 and BCL2 could yield synergistic effects.

\section{Competing interests}

The authors declare that they have no competing interests.

\section{Authors' contributions}

All authors have made substantial contributions to conception and design, acquisition of data, analysis and interpretation of data. All authors have been involved in drafting the manuscript or revising it critically for important intellectual content and have given final approval of the version to be published.

\section{Acknowledgements}

This research was supported by grants from KIKA foundation, SKK and Netherlands Cancer Foundation.

\section{Author details}

'Department of Oncogenomics, Academic Medical Center, University of Amsterdam, Meibergdreef 15, PO box 22700, Amsterdam, AZ 1105, The Netherlands. ${ }^{2}$ Center for Medical Genetics, Ghent University Hospital, Ghent, Belgium. ${ }^{3}$ Department of Pediatric Oncology, Skåne University Hospital, Lund University, Lund, Sweden. ${ }^{4}$ Department of Pediatric Oncology, Emma Kinderziekenhuis, Academic Medical Center, University of Amsterdam, Amsterdam, The Netherlands. ${ }^{5}$ Department of Oncogenomics, M1-132, Academic Medical Center, University of Amsterdam, Meibergdreef 9, Amsterdam, AZ 1105, The Netherlands.

Received: 27 February 2012 Accepted: 26 June 2012

Published: 12 July 2012

\section{References}

1. Hao YY, Sekine K, Kawabata A, Nakamura H, Ishioka T, Ohata H, Katayama R, Hashimoto C, Zhang XD, Noda T, et al: Apollon ubiquitinates SMAC and caspase- 9 , and has an essential cytoprotection function. Nat Cell Biol 2004, 6:849-860.

2. Qiu XB, Goldberg AL: The membrane-associated inhibitor of apoptosis protein, BRUCE/Apollon, antagonizes both the precursor and mature forms of Smac and caspase-9. J Biol Chem 2005, 280:174-182.

3. Buron N, Porceddu M, Brabant M, Desgue D, Racoeur C, Lassalle M, Pechoux $C$, Rustin $P$, Jacotot $E$, Borgne-Sanchez $A$ : Use of human cancer cell lines mitochondria to explore the mechanisms of BH3 Peptides and ABT-737induced mitochondrial membrane permeabilization. PLoS One 2010, 5(3):e9924.

4. Ceballos-Cancino G, Espinosa M, Maldonado V, Melendez-Zajgla J: Regulation of mitochondrial Smac/DIABLO-selective release by survivin. Oncogene 2007, 26:7569-7575.

5. Yu J, Wang P, Ming L, Wood MA, Zhang L: SMAC/Diablo mediates the proapoptotic function of PUMA by regulating PUMA-induced mitochondrial events. Oncogene 2007, 26:4189-4198.

6. Du CY, Fang M, Li YC, Li L, Wang XD: Smac, a mitochondrial protein that promotes cytochrome c-dependent caspase activation by eliminating IAP inhibition. Cell 2000, 102:33-42.

7. Martin SJ: An Apollon vista of death and destruction. Nat Cell Biol 2004, 6:804-806.

8. Pohl $\mathrm{C}$, Jentsch S: Final stages of cytokinesis and midbody ring formation are controlled by BRUCE. Cell 2008, 132:832-845.

9. Sung KW, Choi J, Hwang YK, Lee SJ, Kim HJ, Lee SH, HeeYbo K, Jung HL, $\mathrm{KoO} \mathrm{HH}$ : Overexpression of apollon, an antiapoptotic protein, is associated with poor prognosis in childhood De novo acute myeloid leukemia. Clin Cancer Res 2007, 13:5109-5114.

10. Toujani S, Dessen P, Ithzar N, Danglot G, Richon C, Vassetzky Y, Robert T, Lazar V, Bosq J, Da Costa L, et al: High resolution genome-wide analysis of chromosomal alterations in Burkitt's Lymphoma. PLoS One 2009, 4(9):e7089.

11. Van Houdt WJ, Emmink BL, Pham TV, Piersma SR, Verheem A, Vries RG, Fratantoni SA, Pronk A, Clevers $\mathrm{H}$, Rinkes $\mathrm{HM}$ MB, et al: Comparative proteomics of colon cancer stem cells and differentiated tumor cells identifies BIRC6 as a potential therapeutic target. Mol Cell Proteomics 2011, 10(12):M111.011353. 
12. Brodeur GM: Neuroblastoma: biological insights into a clinical enigma. Nat Rev Cancer 2003, 3:203-216.

13. Maris JM, Hogarty MD, Bagatell R, Cohn SL: Neuroblastoma. Lancet 2007, 369:2106-2120

14. Maris JM: Medical progress: recent advances in neuroblastoma. $N$ Engl J Med 2010, 362:2202-2211.

15. Meyer N, Penn LZ: MYC - TIMELINE Reflecting on 25 years with MYC. Nat Rev Cancer 2008, 8:976-990.

16. Chen YY, Takita J, Choi YL, Kato M, Ohira M, Sanada M, Wang LL, Soda M, Kikuchi A, Igarashi T, et al: Oncogenic mutations of ALK kinase in neuroblastoma. Nature 2008, 455:971-974.

17. George RE, Sanda T, Hanna M, Frohling S, Luther W, Zhang JM, Ahn Y, Zhou WJ, London WB, McGrady $P$, et al: Activating mutations in ALK provide a therapeutic target in neuroblastoma. Nature 2008, 455:975-978.

18. Janoueix-Lerosey I, Lequin D, Brugieres L, Ribeiro A, de Pontual L, Combaret V, Raynal V, Puisieux A, Schleiermacher G, Pierron G, et al: Somatic and germline activating mutations of the ALK kinase receptor in neuroblastoma. Nature 2008, 455:967-970.

19. Janoueix-Lerosey I, Schleiermacher G, Delattre O: Molecular pathogenesis of peripheral neuroblastic tumors. Oncogene 2010, 29:1566-1579.

20. Mosse YP, Laudenslager M, Longo L, Cole KA, Wood A, Attiyeh EF, Laquaglia MJ, Sennett R, Lynch JE, Perri P, et al: Identification of ALK as a major familial neuroblastoma predisposition gene. Nature 2008, 455:930-935.

21. De Brouwer S, De Preter K, Kumps C, Zabrocki P, Porcu M, Westerhout EM, Lakeman A, Vandesompele J, Hoebeeck J, Van Maerken T, et al: Metaanalysis of Neuroblastomas Reveals a Skewed ALK Mutation Spectrum in Tumors with MYCN Amplification. Clin Cancer Res 2010, 16:4353-4362.

22. Van Maerken T, Ferdinande L, Taildeman J, Lambertz I, Yigit N, Vercruysse L, Rihani A, Michaelis M, Cinatl J, Cuvelier CA, et al: Antitumor activity of the selective MDM2 antagonist nutlin-3 against chemoresistant neuroblastoma with wild-type p53. J Natl Cancer Inst 2009, 101:1562-1574.

23. van Noesel MM, Versteeg R: Pediatric neuroblastomas: genetic and epigenetic 'Danse Macabre'. Gene 2004, 325:1-15.

24. Adida C, Berrebi D, Peuchmaur M, Reyes-Mugica M, Altieri DC: Antiapoptosis gene, survivin, and prognosis of neuroblastoma. Lancet 1998, 351:882-883.

25. Islam A, Kageyama H, Takada N, Kawamato T, Takayasu H, Isogai E, Ohira M, Hashizume K, Kobayashi H, Kaneko Y, et al: High expression of Survivin, mapped to $17 q 25$, is significantly associated with poor prognostic factors and promotes cell survival in human neuroblastoma. Oncogene 2000, 19:617-623.

26. Lamers F, van der Ploeg I, Schild L, Ebus ME, Koster J, Hansen BR, Koch T, Versteeg R, Caron HN, Molenaar JJ: Knockdown of Survivin (BIRC5) causes Apoptosis in Neuroblastoma via Mitotic Catastrophe. Endocr Relat Cancer 2011, 18:657-668

27. Giaccone G, Zatloukal P, Roubec J, Floor K, Musil J, Kuta M, van Klaveren RJ, Chaudhary S, Gunther A, Shamsili S: Multicenter Phase II Trial of YM155, a small-molecule suppressor of survivin, in patients with advanced, refractory, non-small-cell lung cancer. J Clin Oncol 2009, 27:4481-4486.

28. Lamers F, Schild L, Koster J, Versteeg R, Caron H, Molenaar J: Targeted BIRC5 silencing using YM155 causes cell death in neuroblastoma cells with low ABCB1 expression. Eur J Cancer 2012, 48(5):763-771.

29. Lewis KD, Samlowski W, Ward J, Catlett J, Cranmer L, Kirkwood J, Lawson D, Whitman E, Gonzalez R: A multi-center phase II evaluation of the small molecule survivin suppressor YM155 in patients with unresectable stage III or IV melanoma. Invest New Drugs 2011, 29(1):161-166.

30. Nakahara T, Takeuchi M, Kinoyama I, Minematsu T, Shirasuna K, Matsuhisa A, Kita A, Tominaga F, Yamanaka K, Kudoh M, et al: YM155, a novel smallmolecule survivin suppressant, induces regression of established human hormone-refractory prostate tumor xenografts. Cancer Res 2007, 67:8014-8021.

31. Satoh T, Okamoto I, Miyazaki M, Morinaga R, Tsuya A, Hasegawa Y, Terashima M, Ueda S, Fukuoka M, Ariyoshi Y, et al: Phase I Study of YM155, a novel survivin suppressant, in patients with advanced solid tumors. Clin Cancer Res 2009, 15:3872-3880.

32. Tolcher AW, Mita A, Lewis LD, Garrett CR, Till E, Daud Al, Patnaik A, Papadopoulos K, Takimoto C, Bartels P, et al: Phase I and Pharmacokinetic Study of YM155, a Small-Molecule Inhibitor of Survivin. J Clin Oncol 2008, 26:5198-5203.
33. Lamers F, Schild L, den Hartog IJM, Ebus ME, Westerhout EM, Ora I, Koster J, Versteeg R, Caron HN, Molenaar JJ: Targeted BCL2 inhibition effectively inhibits Neuroblastoma tumor growth. Eur J Cancer, in press.

34. Santo EE, Ebus ME, Koster J, Schulte JH, Lakeman A, van Sluis P, Vermeulen J, Gisselsson D, Ora I, Lindner S, et al: Oncogenic activation of FOXR1 by 11 q23 intrachromosomal deletion-fusions in neuroblastoma. Oncogene 2012, 31(12):1571-1581.

35. Molenaar JJ, Ebus ME, Koster J, van Sluis P, van Noesel CJM, Versteeg R, Caron HN: Cyclin D1 and CDK4 activity contribute to the undifferentiated phenotype in neuroblastoma. Cancer Res 2008, 68:2599-2609.

36. Fix A, Lucchesi C, Ribeiro A, Lequin D, Pierron G, Schleiermacher G, Delattre $O$, Janoueix-Lerosey l: Characterization of amplicons in neuroblastoma: high-resolution mapping using DNA microarrays, relationship with outcome, and identification of overexpressed genes. Genes Chromosomes Cancer 2008, 47:819-834

37. Mullenbach R, Lagoda PJL, Welter C: An efficient salt-chloroform extraction of dna from blood and tissues. Trends Genet 1989, 5:391.

38. Ren JY, Shi MG, Liu RS, Yang QH, Johnson T, Skarnes WC, Du CY: The Birc6 (Bruce) gene regulates $\mathrm{p} 53$ and the mitochondrial pathway of apoptosis and is essential for mouse embryonic development. Proc Natl Acad SCi USA 2005, 102:565-570.

39. Basu A, Adkins B, Basu C: Down-regulation of caspase-2 by rottlerin via protein kinase c-delta-independent pathway. Cancer Res 2008, 68:2795-2802.

40. Nutt LK, Margolis SS, Jensen M, Herman CE, Dunphy WG, Rathmell JC, Kornbluth S: Metabolic regulation of oocyte cell death through the CaMKII-mediated phosphorylation of caspase-2. Cell 2005, 123:89-103.

41. Shen J, Vakifahmetoglu H, Stridh H, Zhivotovsky B, Wiman KG: PRIMA-1 (MET) induces mitochondrial apoptosis through activation of caspase- 2 . Oncogene 2008, 27:6571-6580.

42. Wolf M, Korja M, Karhu R, Edgren H, Kilpinen S, Ojala K, Mousses S, Kallioniemi A, Haapasalo $\mathrm{H}$ : Array-based gene expression, $\mathrm{CGH}$ and tissue data defines a 12q24 gain in neuroblastic tumors with prognostic implication. BMC Cancer 2010, 10:181.

43. Lestini BJ, Goldsmith KC, Fluchel MN, Liu XY, Chen NL, Goyal B, Pawel BR, Hogarty MD: Mcl1 downregulation sensitizes neuroblastoma to cytotoxic chemotherapy and small molecule Bcl2-family antagonists. Cancer Biol Ther 2009, 8:1587-1595.

44. Kushnareva Y, Newmeyer DD: Bioenergetics and cell death. Mitochondrial Res Transl Med 2010, 1201:50-57.

45. Ekert PG, Silke J, Hawkins CJ, Verhagen AM, Vaux DL: DIABLO promotes apoptosis by removing MIHA/XIAP from processed caspase 9. J Cell Biol 2001, 152:483-490.

46. Teitz T, Wei T, Liu D, Valentine V, Valentine M, Grenet J, Lahti JM, Kidd VJ: Caspase- 9 and Apaf- 1 are expressed and functionally active in human neuroblastoma tumor cell lines with 1 p36 LOH and amplified MYCN. Oncogene 2002, 21:1848-1858.

doi:10.1186/1471-2407-12-285

Cite this article as: Lamers et al:: Identification of BIRC6 as a novel intervention target for neuroblastoma therapy. BMC Cancer 2012 12:285.

\section{Submit your next manuscript to BioMed Central and take full advantage of:}

- Convenient online submission

- Thorough peer review

- No space constraints or color figure charges

- Immediate publication on acceptance

- Inclusion in PubMed, CAS, Scopus and Google Scholar

- Research which is freely available for redistribution 